\title{
Communication Interface Adapter Berbasis Mikrokontroler Arduino Terkendali Sinyal Dual Tone Multi Frequency
}

\author{
Ika Setyawibawa $^{1)}$ dan Arief Goeritno ${ }^{2)}$ \\ 1) PT Panorama Graha Teknologi, Jakarta, INDONESIA \\ Alumni Konsentrasi Teknik Elektronika pada Program Studi Teknik Elektro, Universitas Ibn Khaldun Bogor \\ ${ }^{2)}$ Program Studi Teknik Elektro, Universitas Ibn Khaldun Bogor, JB, INDONESIA \\ email: ${ }^{1)}$ ika_setyo82@gmail.com, ${ }^{2)}$ arief.goeritno@uika-bogor.ac.id
}

\begin{abstract}
Abstrak- Telah dipabrikasi dua modul elektronika sebagai gateway untuk sebuah sistem communication interface adapter (CIA) berbasis mikrokontroler Arduino UNO R3 dan MEGA2560 R3 terkendali sinyal dual tone multi frequency. Sistem CIA bersifat unik, karena sebagai penghubung sistem komunikasi dengan protokol berbeda. Keterwujudan sistem CIA dilakukan melalui tahapan integrasi terhadap perangkat keras dan subsistem pendukung, pemrograman, dan uji verifikasi berupa simulasi. Mikrokontroler Arduino UNO R3 digunakan pada modul gateway ke-1, sedangkan Arduino MEGA2560 R3 digunakan pada modul gateway ke-2. Pemrograman terhadap sistem mikrokontroler dilakukan melalui 5 (lima) tahapan algoritma, yaitu konfigurasi pin, deklarasi variable dan konstanta, ambil dan kirim data, dan keluaran. Struktur sintaks pemrograman didasarkan kepada Arduino Integrated Developtment Enviroenment (IDE). Uji verifikasi dilakukan dalam bentuk simulasi. Diperoleh hasil simulasi terhadap 6 (enam) kondisi, yaitu a) simulasi terhadap rangkaian deteksi dering, b) simulasi terhadap rangkaian Voice Operated Transmit (VOX), c) simulasi rangkaian off hook modul pesawat telepon, d) simulasi imulasi terhadap rangkaian tone decoder, e) simulasi dial up nomor telepon melalui tombol DTMF dan rangkaian IC switching, dan f) simulasi terhadap rangkaian perekam dan penyimpan suara, berupa (i) perekaman suara dan (ii) pemutaran kembali suara. Keberhasilan uji verifikasi dengan 6 kondisi telah sebagai petunjuk, bahwa sistem CIA berbasis mikrokontroler Arduino berfungsi sebagaimana yang diharapkan.
\end{abstract}

Kata Kunci: communication interface adapter, mikrokontroler Arduino, sinyal dual tone multi frequency

\section{Pendahuluan}

Keberadaan perangkat sistem telekomunikasi pada era sekarang, meliputi perangkat untuk 4 (empat) sistem [1], yaitu: (i) telepon tetap (fixed phone), (ii) telepon bergerak (mobile phone), (iii) komunikasi radio (SKR, Radio Communication System, RCS) atau dikenal dengan istilah sistem telekomunikasi dengan frekuensi radio, dan (iv) telepon satelit. Sistem telepon tetap atau lebih dikenal dengan Public Switched Telephone Network (PSTN) [2-4] sebagai jaringan berbasis rangkaian elektronika dengan layanan konvensional teleponi atau Plain Old Telephone Service (POTS) [3,4] yang secara umum diatur oleh standarstandar teknis yang dibuat the International Telecommunication Union (ITU) [5] pada Sektor Standardisasi Telekomunikasi atau ITU-T dengan penggunaan pengalamatan E.163/E.164 yang dikenal dengan nomor telepon [5]. Sistem telepon bergerak, merupakan sistem telekomunikasi berbasis jaringan Global System for Mobile Communications (GSM). Pengenalan pertama kali GSM secara komersial dimulai pada Desember 1991 oleh operator pemenang dari Negara Finlandia [6]. Sistem komunikasi radio, merupakan hubungan komunikasi dengan penggunaan media udara dan frekuensi gelombang radio (radio frequency) sebagai sinyal pembawa informasi, baik informasi bersifat data atau audio [7,8]. Sistem telekomunikasi dengan telepon satelit (satellite telephone, satellite phone, atau satphone), merupakan tipe mobile phone yang terhubung ke satelit pada orbitnya, bukan berdasarkan komunikasi terestrial (permukaan bumi) $[9,10]$.

Perbedaan sistem telekomunikasi telah menjadi pilihan dalam pemanfaatannya. Perangkat elekronika sebagai jembatan untuk penggabungan antara sistem teleponi (fixed phone dan/atau mobile phone) dan sistem komunikasi radio telah menjadi suatu keniscayaan. Penggabungan komunikasi kedua perangkat komunikasi tersebut, dikendalikan oleh pengguna melalui penekanan terhadap tombol pada keypad [11] yang dikenal dengan Dual Tone Multi Frequency (DTMF) [12,13] yang terdapat pada masing-masing perangkat telepon atau perangkat radio. Sistem Communication Interface Adapter (CIA) [14,15] berbasis mikrokontroler terkendali sinyal DTMF bersifat unik sebagai penghubung sistem komunikasi dengan protokol berbeda. Keberadaan sistem CIA sebagai penghubung antara perangkat komunikasi berbasis sistem komunikasi radio [7,8] dan berbasis teleponi (fixed phone atau mobile phone) [3,4] yang didasarkan kepada komunikasi di permukaan bumi (terrestrial) $[9,10]$.

Berpedoman kepada latar belakang tersebut, maka dibuat modul CIA berjumlah 2 (dua) buah sebagai perangkat gateway untuk antarmuka (interface). Sebuah gateway terhubung ke perangkat komunikasi berbasis frekuensi radio dan sebuah gateway lainnya terhubung ke perangkat komunikasi berbasis teleponi (fixed phone atau mobile phone). Diagram blok modul gateway berbasis mikrokontroler terkendali sinyal DTMF unuk CIA, seperti ditunjukkan pada Gambar 1. 


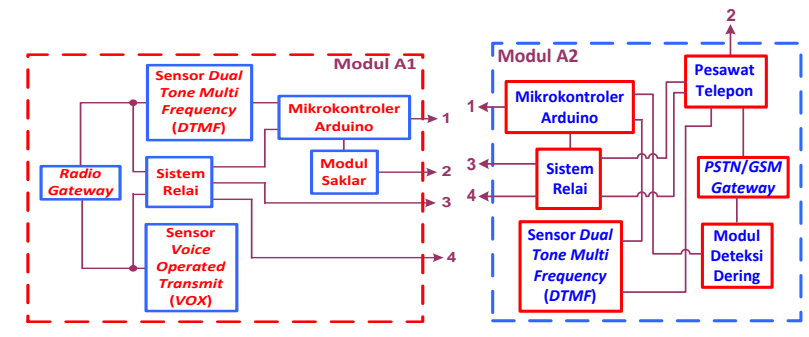

Gambar 1. Diagram blok modul gateway berbasis mikrokontroler terkendali sinyal DTMF untuk CIA

Berdasarkan Gambar 1 ditunjukkan, bahwa sistem berbasis mikrokontroler [16] dapat dikendalikan secara otomatis oleh pengguna melalui nada-nada DTMF [12,13]. Keberadaan CIA terhubung ke sebuah mikrokontroler yang berfungsi sebagai pengolah dan penentu sinyal masukan/keluaran $(I / O)$ [14,15] dari rangkaian sensor, rangkaian pendukung, dan rangkaian penggerak relai $[17,18]$. Pengguna (end user) dapat tersambung atau terputus melalui penekanan kode angka pada keypad yang terdapat pada perangkat komunikasi yang digunakan. Berpedoman kepada rumusan masalah, maka ditetapkan tujuan penelitian yang meliputi a) memperoleh sistem CIA terintegrasi berbasis mikrokontroler Arduino UNO R3 dan MEGA2560 R3 [19] berbantuan keseluruhan perangkat keras dan subsistem pendukung, b) memperoleh struktur pemrograman terhadap sistem mikrokontroler Arduino UNO R3 dan MEGA2560 R3 berbasis Arduino Integrated Development Environment [20], dan c) memperoleh uji verifikasi terhadap sistem CIA terintegrasi berbasis mikrokontroler melalui pemberian simulasi pada jalur masukan dan pengamatan terhadap jalur keluaran.

\section{Metodologi Penelitian}

Untuk dukungan kepada pelaksanaan metode penelitian, diperlukan bahan penelitian berupa: (i) modul DTMF [12,13], modul Voice Operated Transmit (VOX) [21], modul perekam ISD2560 [22], rangkaian tone decoder [23], dan modul telepon PSTN [3,4], (ii) perangkat radio transceiver $[8,13,24]$, (iii) perangkat GSM to analog phone converter [25], (iv) board mikrokontroler Arduino UNO R3 dan MEGA2560 R3 [19,20], (v) sejumlah resistor, sejumlah IC 4066, kapasitor, transistor, relai elektromekanik, dan dioda, (vi) IC regulator 7805, (vii) catu daya (power supply 5 dan $12 \mathrm{Vdc}$ ), (viii) downloader mikrokontroler, dan (ix) program aplikasi Easily Application Graphical Layout Editor (EAGLE) [26]. Alat-alat yang digunakan meliputi: (i) satu set tools elektronika, (ii) avometer, (iii) bor listrik, (iv) minidril, (v) radio digital test set, dan (vi) transmission line tester.

Diagram alir metode penelitian, seperti ditunjukkan pada Gambar 2.

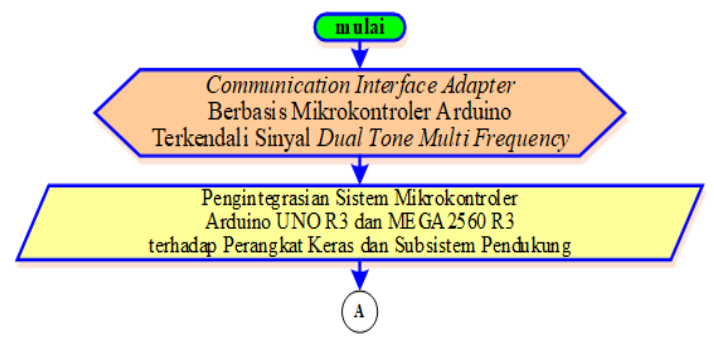

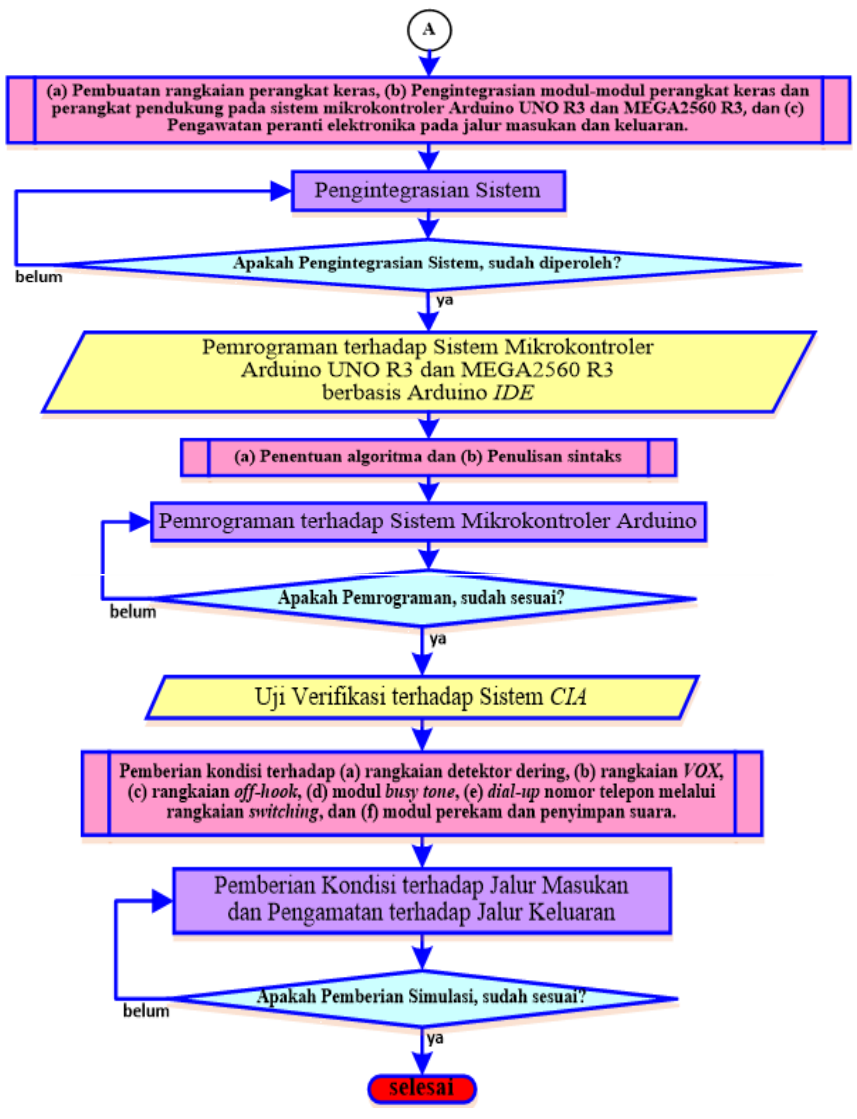

Gambar 2. Diagram alir metode penelitian

Berdasarkan Gambar 2 dijelaskan dengan acuan tujuan penelitian. Pengintegrasian sistem berbasis mikrokontroler Arduino UNO R3 dan MEGA2560 R3 terhadap perangkat keras dan subsistem pendukung, dilakukan melalui pembuatan rangkaian perangkat keras, pengintegrasian modul-modul perangkat keras dan perangkat pendukung pada sistem mikrokontroler Arduino UNO R3 dan MEGA2560 R3, dan pengawatan peranti elektronika pada jalur masukan dan keluaran yang terhubung ke sistem radio dan teleponi. Struktur pemrograman terhadap sistem mikrokontroler Arduino UNO R3 dan MEGA2560 R3, dilakukan melalui penentuan algoritma dalam bentuk diagram alir dan penulisan sintaks yang berbasis Arduino $I D E$. Pelaksanaan uji verifikasi berupa simulasi terhadap sistem CIA, meliputi pemberian kondisi terhadap jalur masukan dan diamati kondisi keluaran. Pemberian kondisi terhadap jalur masukan dilakukan kepada rangkaian detektor dering, rangkaian Voice Operated Transmit (VOX), rangkaian off-hook terhadap perangkat telepon, modul busy tone, dial-up nomor telepon melalui rangkaian switching, dan modul perekam dan penyimpan suara.

\section{Hasil dan Pembahasan}

Diagram blok hubungan antar modul gateway pada sistem CIA terintegrasi berbasis mikrokontroler terkendali sinyal $D T M F$, seperti ditunjukkan pada Gambar 3. 


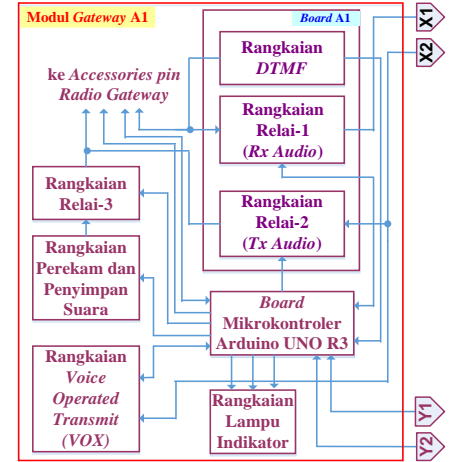

modul gateway $\mathrm{A} 1$

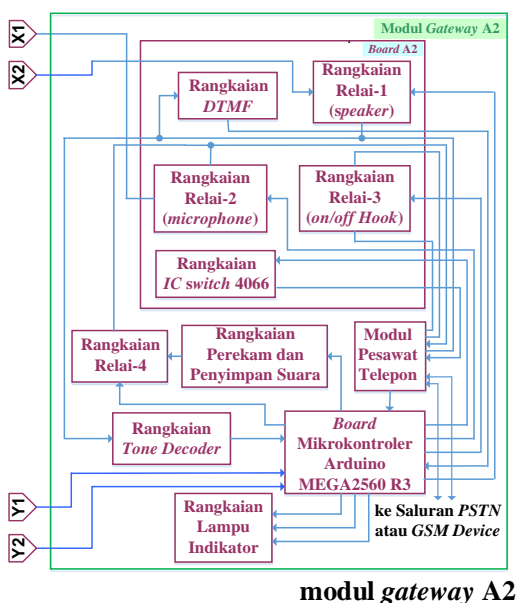

Gambar 3 Diagram blok hubungan antar modul gateway pada sistem CIA terintegrasi berbasis mikrokontroler terkendali sinyal $D T M F$

\section{A Sistem CIA Terintegrasi Berbasis Mikrokontroler Arduino UNO R3 dan MEGA2560 R3}

Sistem CIA terintegrasi berbasis mikrokontroler terkendali sinyal DTMF merupakan sistem yang terdiri atas beberapa rangkaian dan komponen elektronika yang diintegrasikan menjadi satu kesatuan, agar sistem tersebut dapat beroperasi secara optimal. Sistem CIA terintegrasi berbasis mikrokontroler terkendali sinyal $D T M F$, seperti ditunjukkan pada Gambar 4.

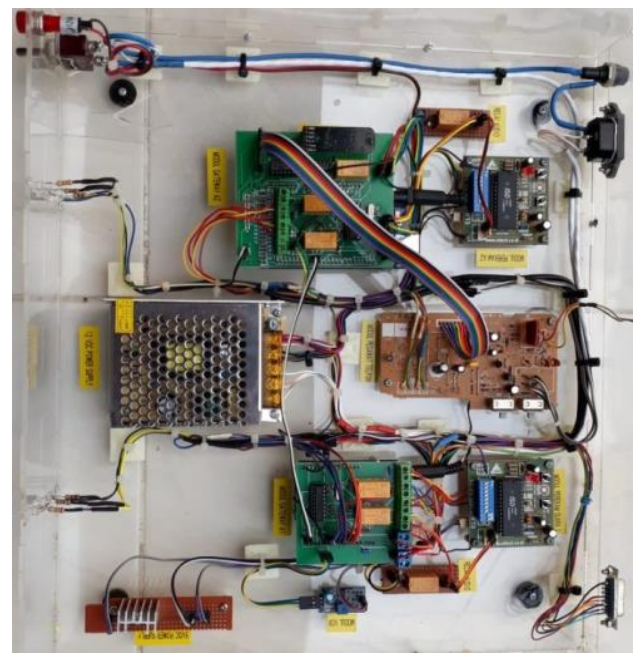

Gambar 4 Sistem CIA terintegrasi berbasis mikrokontroler terkendali sinyal DTMF
Berdasarkan Gambar 4 ditunjukkan, bahwa sistem CIA terintegrasi berbasis mikrokontroler Arduino UNO R3 dan MEGA2560 R3, meliputi (i) modul gateway A1 yang merupakan antarmuka untuk sistem komunikasi berbasis frekuensi radio, (ii) modul gateway A2 yang merupakan antarmuka untuk sistem komunikasi berbasis teleponi, dan (iii) sistem catu daya.

Board mikrokontroler Arduino UNO R3 difungsikan untuk pengolahan data masukan dan keluaran $(I / O)$ pada modul gateway A1. Koneksi pin-pin jalur masukan dan keluaran pada Arduino UNO R3 di modul gateway A1, seperti ditunjukkan pada Gambar 5.

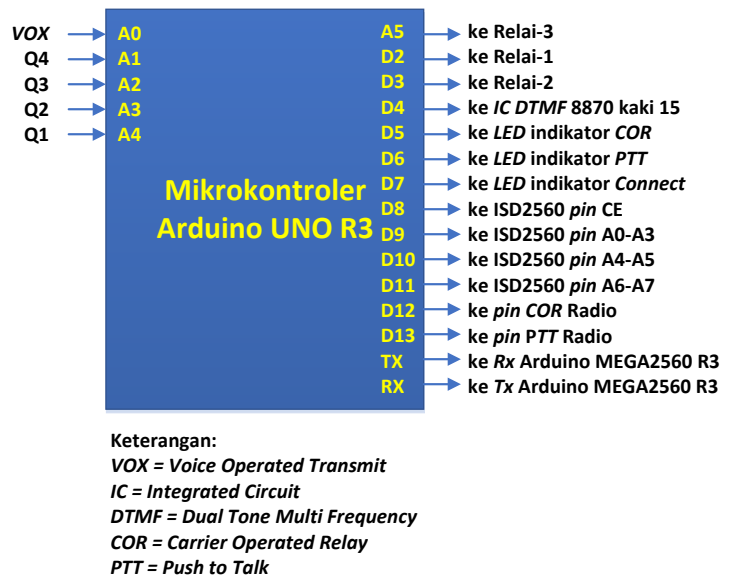

Gambar 5 Koneksi pin-pin jalur masukan dan keluaran pada Arduino UNO R3 di modul gateway A1

Board mikrokontroler Arduino UNO R3 terhubung dengan board mikrokontroler Arduino MEGA2560 R3 di modul gateway A2 melalui pin data $T X / R X$ yang digunakan sebagai jalur komunikasi data secara terus- menerus.

Board mikrokontroler Arduino MEGA2560 R3 difungsikan untuk pengolahan data masukan dan keluaran pada modul gateway A2. Koneksi pin-pin jalur masukan dan keluaran pada Arduino MEGA2560 R3 di modul gateway A2, seperti ditunjukkan pada Gambar 6 .

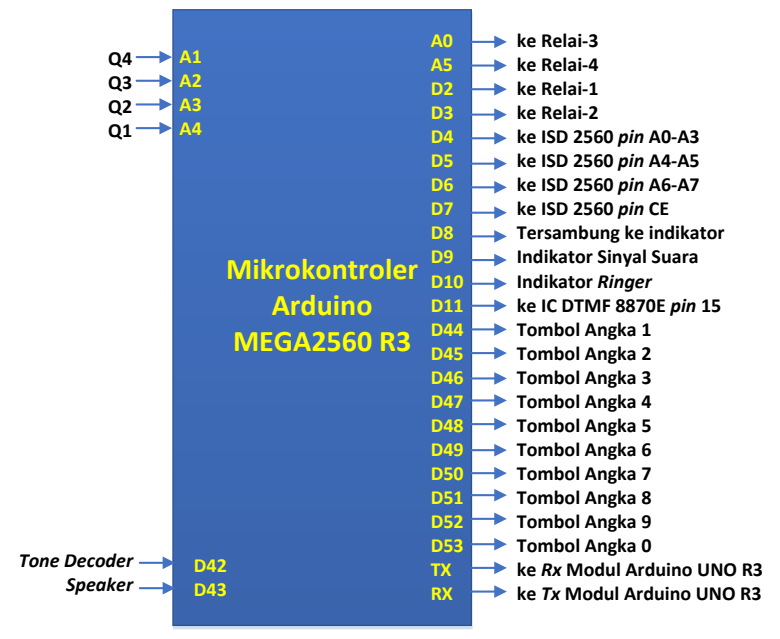

Gambar 6 Koneksi pin-pin jalur masukan dan keluaran pada Arduino MEGA2560 R3 di modul gateway A2 
Berdasarkan Gambar 6 ditunjukkan, bahwa selain keterhubungan dengan beberapa rangkaian yang berada di modul gateway A2, board mikrokontroler Arduino MEGA2560 R3 juga terhubung ke board mikrokontroler Arduino UNO R3 di modul gateway A1 melalui pin data $T X / R X$ yang digunakan sebagai jalur komunikasi data secara terus menerus

\section{B Pemrograman terhadap Sistem Mikrokontroler Arduino UNO R3 dan MEGA2560 R3}

Pemrograman terhadap mikrokontroler Arduino UNO R3 dan Arduino MEGA2560 R3 digunakan aplikasi Arduino $I D E$ yang merupakan aplikasi bawaan dari Arduino dengan penggunaan bahasa pemrograman $\mathrm{C}$. Tahapan pemrograman yang harus dilalui, meliputi penentuan algoritma dan penulisan sintaks.

\section{B.1 Penentuan algoritma}

Penentuan algoritma dengan tujuan untuk kemudahan dalam pelaksanaan pemrograman, agar terarah dan terstruktur dengan baik. Algoritma yang dibuat dalam program tertanam (embedded program) terhadap sistem CIA berbasis mikrokontroler, dilakukan terhadap mikrokontroler Arduino UNO R3 dan Arduino MEGA2560 R3. Algoritma dibuat dalam bentuk diagram alir. Diagram alir pemrograman sistem $C I A$ terintegrasi berbasis mikrokontroler terkendali sinyal $D T M F$, seperti ditunjukkan pada Gambar 7.

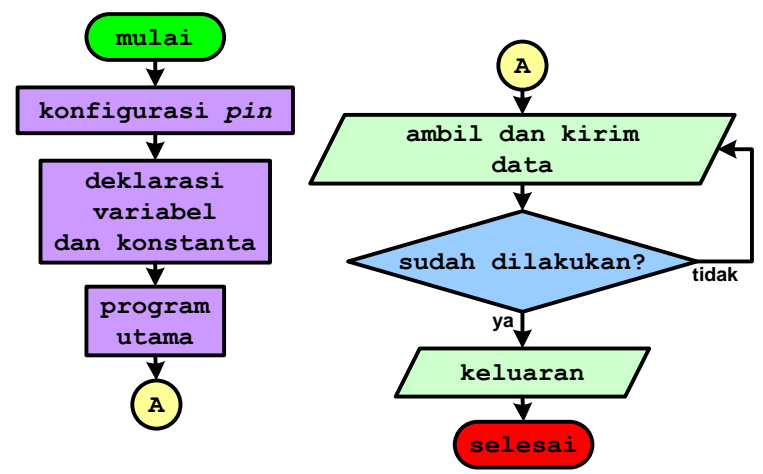

Gambar 7 Diagram alir pemrograman sistem CIA terintegrasi berbasis mikrokontroler terkendali sinyal DTMF

Berdasarkan Gambar 7 ditunjukkan, bahwa struktur program pada sistem minimum terdiri atas beberapa tahapan, yaitu: (i) konfigurasi pin, (ii) deklarasi variabel dan konstanta, (iii) program utama, (iv) ambil dan kirim data, dan (v) keluaran.

\section{B.2 Penulisan sintaks}

Dalam aplikasi Arduino IDE penulisan sintaks lebih dikenal secara umum dengan istilah sketch. Keseluruhan penulisan sintaks didasarkan kepada algoritma.

\section{\#1) Konfigurasi pin}

Tahapan konfigurasi pin merupakan tahapan penentuan pin yang digunakan sebagai keluaran atau sebagai masukan. Pin digunakan sebagai parameter dalam program di mikrokontroler Arduino UNO R3 dan MEGA2560 R3 yang terhubung ke rangkaian $V O X$, rangkaian $D T M F$, rangkaian tone decoder, dan pin Carrier Operated Relay (COR), rangkaian relai, rangkaian perekam dan penyimpan suara, dan rangkaian $I C$ switch. Penulisan struktur sintaks untuk konfigurasi pin, seperti ditunjukkan pada Tabel 1.

Tabel 1 Penulisan struktur sintaks untuk konfigurasi pin

\begin{tabular}{|c|c|}
\hline Modul Gateway A1 & Modul Gateway A2 \\
\hline $\begin{array}{l}\text { int fox }=\mathrm{A} 0 ; \\
\text { int relay }=\mathrm{A} 5 \\
\text { int } \mathrm{q} 1=\mathrm{A} 4 ; \\
\text { int } \mathrm{q} 2=\mathrm{A} 3 ; \\
\text { int } \mathrm{q}=\mathrm{A} 2 ; \\
\text { int } \mathrm{q} 4=\mathrm{A} 1 ; \\
\text { int } \mathrm{rs}=3 ; \\
\text { int } \mathrm{rm}=2 ; \\
\text { int play }=8 ; \\
\text { int ch1 }=11 ; \\
\text { int ch2 }=10 ; \\
\text { int ch3 }=9 ; \\
\text { int } \operatorname{cor}=12 ; \\
\text { int ptt }=13 ; \\
\text { int lcor }=5 ; \\
\text { int lptt }=6 ; \\
\text { int lind }=7 ; \\
\text { int dtmf }=4 ;\end{array}$ & $\begin{array}{l}\text { int relay }=\mathrm{A} 5 ; \\
\text { int } \mathrm{q} 1=\mathrm{A} 4 ; \\
\text { int } \mathrm{q} 2=\mathrm{A} 3 ; \\
\text { int } \mathrm{q} 3=\mathrm{A} 2 ; \\
\text { int } \mathrm{q} 4=\mathrm{A} 1 ; \\
\text { int dtmf }=11 ; \\
\text { int play }=7 ; \\
\text { int ch1 }=4 ; \\
\text { int ch2 }=5 ; \\
\text { int ch3 }=6 ; \\
\text { int rs }=2 ; \\
\text { int rm }=3 ; \\
\text { int rdet }=43 ; \\
\text { int btone }=42 ; \\
\text { int hold }=\mathrm{A} 0 ; \\
\text { int } 1 \text { tlp }=10 ; \\
\text { int } 1 \mathrm{a} 1=8 ; \\
\text { int } 1 \text { suara }=9 ; \\
\text { int -0 }=44 ; \\
\text { int }-1=45 ; \\
\text { int }-2=46 ; \\
\text { int }-3=47 ; \\
\text { int }-4=48 ; \\
\text { int }-5=49 ; \\
\text { int }-6=50 ; \\
\text { int }-7=51 ; \\
\text { int }-8=52 ; \\
\text { int }-9=53 ;\end{array}$ \\
\hline
\end{tabular}

\#2) Deklarasi variabel dan konstanta

Deklarasi variabel dilakukan untuk pendeklarasian jenis data yang harus dilakukan. Penulisan struktur sintaks untuk deklarasi variabel dan konstanta, seperti ditunjukkan pada Tabel 2.

Tabel 2 Penulisan struktur sintaks untuk deklarasi variabel dan konstanta

\begin{tabular}{ll}
\hline \multicolumn{1}{c}{ Modul Gateway A1 } & \multicolumn{1}{c}{ Modul Gateway A2 } \\
\hline String modul = "01"; & String modul = "02"; \\
char $i ;$ & const long dialtone $=50 ;$ \\
char dat $;$ & const long ringtone $=35 ;$ \\
int nilai $=0 ;$ & const long busytone $=20 ;$ \\
int cont $=0 ;$ & unsigned long milis $=0 ;$ \\
String data =" ; & String kondisi $;$ \\
String input =""; & char angka; \\
unsigned long milis $=0 ;$ & String input =" ; \\
& String data $=" ;$ \\
& char $i ;$ \\
& int cont $=0 ;$ \\
& int nilai $=0 ;$ \\
& int dat $=0 ;$ \\
\end{tabular}

\#3) Program utama

Sumber dari semua pengontrolan program terletak di blok program utama. Semua perintah pada program diurutkan diurutkan di program utama, mulai dari kondisi awal, pengambilan data, dan reaksi atau keluaran dari program yang dibuat. Penulisan struktur sintaks untuk program utama pada modul gateway A1, yaitu:

void loop () \{

if $($ Serial . available ()$>0)$ (data $=$ Serial .readString ()$;\}$

if (data $==$ modul)

delay (200);

Serial.print("connected")

digitalWrite(lind, HIGH);

telpon();

\} data $=" "$

while (digitalRead (cor)==LOW and $i$ != 'a') ( digitalWrite(lcor, HIGH);

if (digitalRead (dtmf)==HIGH) (nomor (); if (i !=

'a') $\{$ input $+=i ;\}\}$

if $\left(i==a^{\prime}\right)\{i=1$, ; setnomor ()$;\}$

Serial.print (digitalRead (q2)):

Serial.print (digitalRead (q3)); 
Untuk modul gateway A2, yaitu:

void loop () i

dat $=0$;

input $=" "$

if (Serial.available ()$>0)$ data $=$ Serial.readString ()$;\}$

if (data $==$ "tutup") \{digitalWrite (la1, LOW); data = ""; return; \}

if (data $==$ modul) \{

digitalWrite (hold, HIGH)

Serial.print("02 ready");

digitalWrite (la1, HIGH) ;

while (dat $!=60)\{$

unsigned long awalmilis = millis () ;

if (awalmilis - milis $>=100)$

milis = awalmilis

dat++; \}

if (digitalRead (btone) == LOW) \{nilait+;

digitalWrite (hold, LOW);

dat $=0$;

if (nilai >= dialtone) \{Serial.print("o");

else \{digitalWrite(la1, LOW); Serial.print(" ");\} nilai $=0$

\#4) Ambil dan kirim data

Ambil dan kirim data merupakan perintah atau ketentuan yang sesuai dengan masukan pada sensor tersebut dikirim untuk dan selanjutnya digunakan sebagai isyarat ke penggerak aktuator berupa relai. Penulisan struktur sintaks untuk program ambil dan kirim data, seperti ditunjukkan pada Tabel 3.

Tabel 3 Penulisan sintaks untuk program ambil dan kirim data

\begin{tabular}{|c|c|}
\hline Modul Gateway A1 & Modul Gateway A2 \\
\hline void nomor () \{ & void nomor () \{ \\
\hline$i=1$ & $i=1$ \\
\hline delay (200); & delay (200); \\
\hline int $\mathrm{d} 1 \mathrm{l}=$ & int $\mathrm{d} 1=$ \\
\hline digitalRead (q1) ; & digitalRead (q1) ; \\
\hline int $\mathrm{d} 2=$ & int $\mathrm{d} 2=$ \\
\hline $\begin{array}{l}\text { digitalRead (q2) } \\
\text { int } \mathrm{d} 3=\end{array}$ & $\begin{array}{l}\text { digitalRead (q2) } \\
\text { int } d 3=\end{array}$ \\
\hline digitalRead (q3) ; & digitalRead (q3) ; \\
\hline int $\mathrm{d} 4=$ & int $d 4=$ \\
\hline digitalRead (q4); & digitalRead (q4); \\
\hline
\end{tabular}

\#5) Keluaran

Keluaran merupakan reaksi yang diakibatkan oleh masukan data yang diberikan sensor dan dihubungkan ke pin pada port masukan mikrokontroler. Kondisi keluaran program digunakan untuk penghubungan ke rangkaian relai, rangkaian perekam dan panyimpan suara, dan rangkaian $I C$ switch. Penulisan struktur sintaks untuk keluaran, seperti ditunjukkan pada Tabel 4.

Tabel 4 Penulisan struktur sintaks untuk keluaran

\begin{tabular}{|c|c|}
\hline Modul Gateway A1 & Modul Gateway A2 \\
\hline $\begin{array}{l}\text { void suaral() \{ } \\
\text { digitalWrite (ch1, LOW); } \\
\text { digitalWrite (ch2, HIGH); } \\
\text { digitalWrite (ch3, HIGH); } \\
\text { digitalWrite (ptt, LOW); } \\
\text { digitalWrite (lptt, HIGH); } \\
\text { delay(200); } \\
\text { digitalWrite (relay, HIGH); } \\
\text { digitalWrite (play, LOW); } \\
\text { digitalWrite (ptt, LOW); } \\
\text { delay(6000); } \\
\text { suaraclear(); } \\
\text { \} }\end{array}$ & $\begin{array}{l}\text { void suara1 () ( } \\
\text { digitalWrite (ch1, LOW); } \\
\text { digitalWrite (ch2, HIGH); } \\
\text { digitalWrite (ch3, HIGH); } \\
\text { delay (200); } \\
\text { digitalWrite (relay, } \\
\text { HIGH); } \\
\text { digitalWrite (play, LOW); } \\
\text { delay (4300); } \\
\text { suaraclear(); } \\
\text { f }\end{array}$ \\
\hline
\end{tabular}

\section{Uji Verifikasi}

Kepastian rangkaian terpasang di minimum system berbasis mikrokontroler terkendali oleh sinyal DTMF untuk CIA telah beroperasi dengan baik, dilakukan uji verifikasi terhadap beberapa rangkaian dan modul dalam bentuk simulasi. Uji verifikasi pada setiap rangkaian dilakukan dengan cara pemberian masukan dan dilakukan pengamatan pada jalur keluaran dengan peralatan yang sesuai. Uji verifikasi juga berfungsi untuk pengamatan terhadap keberadaan jabat-tangan (handshaking) antar modul atau rangkaian. Terdapat 6 (enam) simulasi, yaitu a) simulasi terhadap rangkaian deteksi dering, b) simulasi terhadap rangkaian Voice Operated Transmit (VOX), c) simulasi rangkaian off/on hook modul pesawat telepon, d) simulasi imulasi terhadap rangkaian tone decoder, e) simulasi dial up nomor telepon melalui tombol $D T M F$ dan rangkaian $I C$ switching, dan f) simulasi terhadap rangkaian perekam dan penyimpan suara, berupa (i) perekaman suara dan (ii) pemutaran kembali suara.

\section{C.1 Simulasi terhadap rangkaian deteksi dering}

Sebelum dilakukan simulasi pengkondisian terhadap rangkaian pendeteksi dering, langkah awal yang harus dilakukan berupa pengukuran nilai tegangan di jalur speaker dering pada modul pesawat telepon saat terdapat ada pangilan telepon dan pada saat tidak terdapat panggilan telepon. Hasil pengukuran tegangan ini yang digunakan sebagai dasar penentuan kondisi awal pin D43 pada mikrokontroler Arduino MEGA2560 R3. Simulasi rangkaian dering dilakukan dengan pengubahan logika masukan di pin D43 mikrokontroler Arduino MEGA2560 R3 sebagai logika high atau low sesuai dengan setpoint yang telah ditentukan. Hasil pengukuran tegangan pada saat terdapat dan tidak terdapat panggilan masuk, seperti ditunjukkan pada Tabel 5.

Tabel 5 Hasil pengukuran tegangan pada saat terdapat dan tidak terdapat panggilan masuk

\begin{tabular}{lc}
\hline \multicolumn{1}{c}{ Kondisi } & $\begin{array}{c}\text { Tegangan } \\
(\mathrm{V} d c)\end{array}$ \\
\hline Tidak terdapat dering & 0,931 \\
Terdapat dering & 13,37 \\
\hline
\end{tabular}

\section{C.2 Simulasi terhadap rangkaian Voice Operated Transmit}

Rangkain Voice Operated Transmit (VOX) berfungsi untuk pendeteksian sinyal suara saat komunikasi sedang berlangsung. Keluaran pada pin dari rangkaian terhubung ke mikrokontroler di pin A0. Untuk keperluan pendeteksian sinyal suara, perlu dilakukan pengaturan pada resistor variabel yang terdapat pada rangkaian, sehingga diperoleh data digital 0 dan 1 . Simulasi pada rangkaian VOX dilakukan dengan pemberian masukan berupa sinyal suara dengan penggunaan radio digital test set Aeroflex tipe 3920 untuk pengaktifan fitur Audio Frequency Generator (AF Generator). Alat ukur disetel pada nilai frekuensi sinyal suara yang dapat didengar manusia, yaitu dalam rentang 20 20 kilohertz dengan level tegangan tidak lebih dari 200 milivolt. Port keluaran audio dihubungkan ke pin masukan rangkaian VOX. Pengetesan dilakukan dengan alat ukur dengan penyetelan nilai frekuensi 1 kilohertz. dengan level 2,314 milivolt. 
Tampilan penyetelan pada Audio Frequency Generator, seperti ditunjukkan pada Gambar 8.

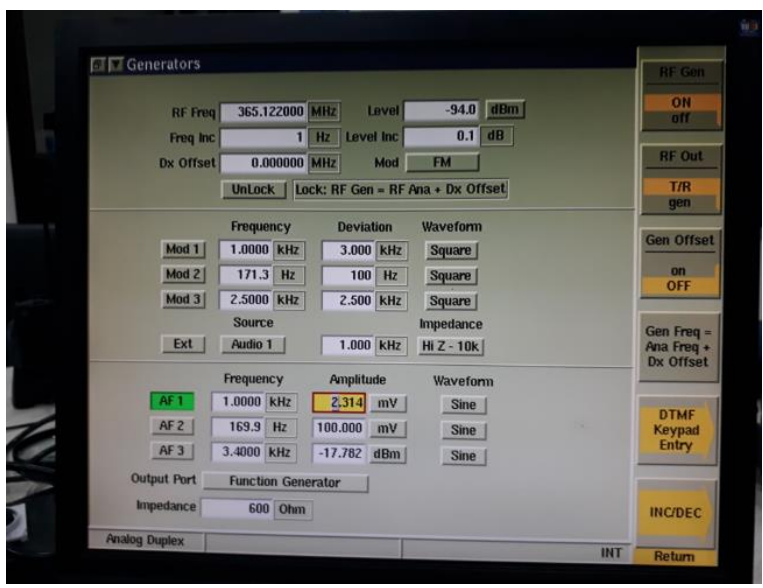

Gambar 8 Tampilan penyetelan pada Audio Frequency Generator

Tampilan saat pengkondisian rangkaian Voice Operated Tramsmit dengan penerimaan masukan sinyal suara dari alat ukur, seperti ditunjukkan pada Gambar 9.

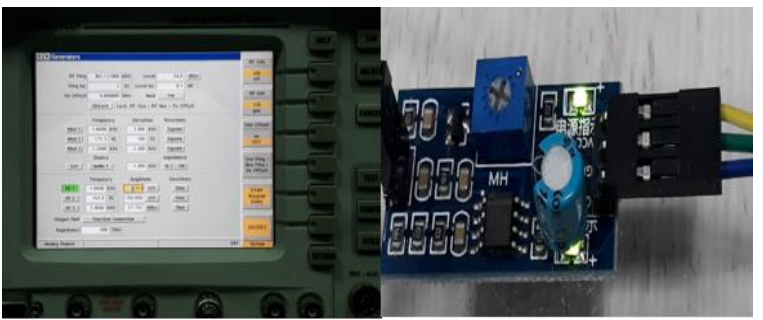

Gambar 9 Tampilan saat pengkondisian rangkaian Voice Operated Tramsmit dengan penerimaan masukan sinyal suara dari alat ukur

\section{C.3 Simulasi terhadap rangkaian off/on hook}

Rangkaian off/on hook modul pesawat telepon berupa rangakaian relai yang dipasang pada modul gateway A2 terhubung ke modul pesawat telepon. Modul penggerak relai digunakan sebagai pengganti switch off hook modul pesawat telepon dengan tujuan, agar kondisi off/on hook modul pesawat telepon dapat dikendalikan oleh mikrokontroler. Tampilan relai offlon hook untuk modul pesawat telepon, seperti ditunjukkan pada Gambar 10.

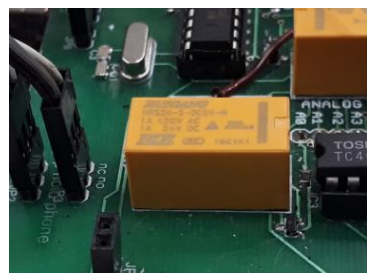

Gambar 10 Tampilan relai off/on hook untuk modul pesawat telepon

Simulasi dilakukan pada saat sistem dengan kondisi terima atau tidak terima panggilan. Saat tidak terima panggilan kondisi kaki relai dalam kondisi Normally Open $(N O)$ dan saat terima panggilan kondisi kaki relai dalam kondisi Normally Close (NC). Kondisi kaki relai rangkaian off/on hook, seperti ditunjukkan pada Tabel 6.
Tabel 6 Kondisi kaki relai rangkaian offlon hook

\begin{tabular}{ccc}
\hline Kondisi & Status Kaki Saklar & Keterangan \\
\hline Saat tidak dilakukan panggilan & Normally Close & on-hook \\
Saat diakukan pangilan & Normally Open & off-hook \\
Saat terima panggilan & Normaly Open & off-hook \\
\hline
\end{tabular}

C.4 Simulasi terhadap rangkaian tone decoder

Keberadaan rangkaian tone decoder pada sistem CIA, digunakan sebagai sensor berbasis frekuensi tone pada jalur telepon pada saat modul pesawat telepon terjadi on hook atau off hook. Perlakuan terhadap rangkaian berupa pengukuran frekuensi tone pada jalur telepon pada (a) saat kondisi modul telepon PSTN off-hook, (b) saat penerimaan sinyal sibuk, dan (c) saat modul telepon terjadi panggilan. Nilai frekuensi pada modul pesawat telepon PSTN dapat diketahui dengan penggunaan alat ukur Radio Digital Test Set merek Aeroflex tipe 3920. Hasil pengukuran frekuensi tone pada modul pesawat telepon, seperti ditunjukkan pada Tabel 7.

Tabel 7 Hasil pengukuran frekuensi tone pada modul pesawat

\begin{tabular}{ccc}
\multicolumn{3}{c}{ telepon } \\
\hline Kondisi & Periode Waktu (detik) & $\begin{array}{c}\text { Frekuensi } \\
\text { (hertz) }\end{array}$ \\
\hline Off-hook & kontinyu & 450 \\
sibuk & 0,5 detik on; 0,5 detik off & 450 \\
dilakukan & 1 detik on; 4 detik off & 450 \\
panggilan & & \\
\hline
\end{tabular}

C.5 Simulasi terhadap rangkaian tombol DTMF dan $I C$ switching

Simulasi pengkondisian terhadap rangkaian DTMF, dgunakan bantuan aplikasi DTMF Encoder sebagai generator sinyal frekuensi $D T M F$ dan alat ukur Radio Digital Test Set merek Aeroflex tipe 3920 untuk penunjukan bentuk gelombang frekuensi sinyal DTMF sesuai dengan tombol angka yang ditekan. Tampilan aplikasi DTMF Encoder untuk simulasi pengkondisian rangkaian $D T M F$, seperti ditunjukkan pada Gambar 11.

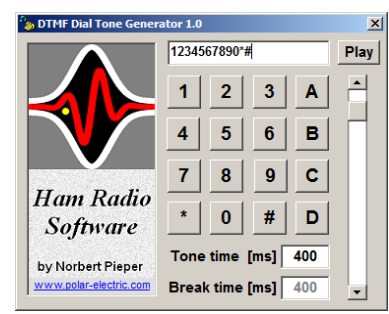

Gambar 11 Tampilan aplikasi DTMF Encoder untuk simulasi pengkondisian rangkaian $D T M F$

Tampilan nilai frekuensi sinyal DTMF pada saat penekanan angka 1, seperti ditunjukkan pada Gambar 12.

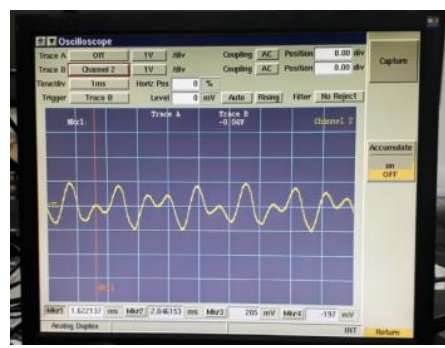

Gambar 12 Tampilan nilai frekuensi sinyal $D T M F$ pada saat penekanan angka 1 
C.6 Simulasi terhadap rangkaian perekam dan penyimpan suara

Simulasi terhadap rangkaian perekam dan penyimpan suara berupa a) perekaman suara dan b) pemutaran kembali suara.

\section{a). Perekaman suara}

Perlakuan saat perekaman suara berupa penentuan alamat dari suara yang direkam. Jumlah suara yang dapat direkam pada rangkaian perekam dan penyimpan suara, seperti ditunjukkan pada Tabel 8.

Tabel 8 Jumlah suara yang dapat direkam pada rangkaian perekam dan penyimpan suara

\begin{tabular}{|c|c|c|c|c|c|}
\hline \multicolumn{3}{|c|}{ di modul gateway A1 } & \multicolumn{3}{|c|}{ di modul gateway A2 } \\
\hline & mat & Suara & & mat & Suara \\
\hline 0000 & 0000 & $\begin{array}{c}\text { Slot tidak } \\
\text { tersedia }\end{array}$ & 0000 & 0000 & $\begin{array}{c}\text { slot tidak } \\
\text { tersedia }\end{array}$ \\
\hline 0000 & 1111 & $\begin{array}{c}\text { 02, tersambung, } \\
\text { masukan nomor } \\
\text { telepon akhiri } \\
\text { dengan tanda } \\
\text { pagar }\end{array}$ & 0000 & 1111 & $\begin{array}{c}\text { masukkan nomor } \\
\text { slot }\end{array}$ \\
\hline 1111 & 0011 & diputus & $\begin{array}{l}1111 \\
1111\end{array}$ & $\begin{array}{l}0011 \\
1100\end{array}$ & $\begin{array}{l}01 \text { tersambung } \\
\text { diputus }\end{array}$ \\
\hline
\end{tabular}

Berdasarkan Tabel 8 ditunjukkan, bahwa pengalamatan suara yang direkam berupa 8 bit data biner melalui pin A0 sampai A7 dengan langkah-langkah (i) setelah diubah posisi saklar S3 (play/record), agar posisi pin $P / R$ terhubung dengan ground; (ii) pengubahan posisi saklar S1, agar pin $P D$ tidak terhubung dengan ground; (iii) penekanan S2 untuk mulai perekaman dengan berbicara di mikrofon; dan (iv) untuk pengakhiran perekaman, diubah posisi saklar S1, agar pin $P D$ terhubung dengan ground dan $\mathrm{S} 2$ dilepas.

\section{b). Pemutaran kembali suara}

Kondisi sistem saat pemunculan kembali suara, seperti ditunjukkan pada Tabel 9.

Tabel 9 Kondisi sistem saat pemunculan kembali suara

\begin{tabular}{|c|c|c|}
\hline Kondisi & Suara & Lokasi \\
\hline $\begin{array}{c}\text { Dari radio } H T \text { melakukan penekanan } \\
\text { tombol 02\# sebelum komunikasi } \\
\text { terhubung }\end{array}$ & $\begin{array}{c}\text { "02 } \\
\text { tersambung, } \\
\text { masukkan } \\
\text { nomor } \\
\text { telepon } \\
\text { akhiri } \\
\text { dengan tanda } \\
\text { pagar" }\end{array}$ & $\begin{array}{l}\text { Modul } \\
\text { gateway } \\
\quad \text { A1 }\end{array}$ \\
\hline $\begin{array}{c}\text { Sebelum modul gateway A1 dan modul } \\
\text { gateway A2 terhubung kemudian dari } \\
\text { radio HT menekan selain tombol } 02 \\
\text { sebelum tanda \# }\end{array}$ & $\begin{array}{l}\text { "slot tidak } \\
\text { tersedia" }\end{array}$ & $\begin{array}{l}\text { Modul } \\
\text { gateway } \\
\quad \text { A1 }\end{array}$ \\
\hline $\begin{array}{l}\text { Saat modul gateway A1 dan modul } \\
\text { gateway A2 terhubung kemudian dari } \\
\text { radio HT atau penelpon menekan } \\
\text { tombol *, dan rangkaian tone } \\
\text { dekoder tidak menerima nada sambung } \\
\text { (dial tone) }\end{array}$ & "diputus" & $\begin{array}{l}\text { Modul } \\
\text { gateway } \\
\text { A1 dan } \\
\text { Modul } \\
\text { gateway } \\
\quad \text { A2 }\end{array}$ \\
\hline $\begin{array}{c}\text { Sebelum modul gateway A1 dan modul } \\
\text { gateway A2 terhubung kemudian } \\
\text { penelpon menekan selain tombol } 01 \\
\text { sebelum tanda \# }\end{array}$ & $\begin{array}{l}\text { "slot tidak } \\
\text { tersedia" }\end{array}$ & $\begin{array}{l}\text { Modul } \\
\text { gateway } \\
\quad \text { A1 }\end{array}$ \\
\hline $\begin{array}{c}\text { Sebelum modul gateway A1 dan modul } \\
\text { gateway A2 terhubung kemudian } \\
\text { rangkaian relai off hook aktif, dan } \\
\text { modul pesawat telepon menerima } \\
\text { panggilan }\end{array}$ & $\begin{array}{l}\text { "Masukkan } \\
\text { nomor slot" }\end{array}$ & $\begin{array}{l}\text { Modul } \\
\text { gateway } \\
\quad \text { A2 }\end{array}$ \\
\hline $\begin{array}{l}\text { Setelah modul pesawat telepon off } \\
\text { hook, penelpon menekan 01\# dari } \\
\text { perangkat telepon yang digunakan }\end{array}$ & $\begin{array}{l}\text { "01 } \\
\text { tersambung" }\end{array}$ & $\begin{array}{l}\text { Modul } \\
\text { gateway } \\
\text { A2 }\end{array}$ \\
\hline $\begin{array}{c}\text { Setelah modul pesawat telepon off } \\
\text { hook, modul gateway A1 dan modul } \\
\text { gateway A2 belum terhubung kemudian } \\
\text { penelpon menekan selain tombol } 01 \\
\text { sebelum tanda \# }\end{array}$ & $\begin{array}{l}\text { "slot tidak } \\
\text { tersedia" }\end{array}$ & $\begin{array}{l}\text { Modul } \\
\text { gateway } \\
\quad \text { A2 }\end{array}$ \\
\hline
\end{tabular}

pemutaran kembali suara yang telah disimpan, dilakukan dengan cara tidak jauh berbeda dengan cara untuk pelaksanaan perekaman. Proses pemanggilan suara tersimpan pada rangkaian perekam dan penyimpan suara dilakukan oleh mikrokontroler dengan pengaktifan port digital jalur keluaran pada pin D8, D9, D10, dan D11 pada mikrokontroler Arduino UNO R3 di modul gateway A1 dan port digital jalur keluaran pada pin D4, D5, D6, dan D7 pada mikrokontroler Arduino MEGA2560 R3 di modul gateway A2.

Untuk pemutaran kembali suara yang telah direkam, dilakukan dengan langkah-langkah (i) Penentuan alamat suara yang direkam melalui pin A0 sampai A7 berupa kombinasi data 8 bit biner; (ii) Pengubahan posisi saklar S3, agar posisi pin $P / R$ tidak terhubung dengan ground; (iii) Pengubahan posisi saklar S1, agar pin $P D$ tidak terhubung dengan ground; dan (iv) Penekanan tombol S2, agar suara terekam pada alamat yang sudah ditentukan dapat terdengar di loudspeaker.

\section{Kesimpulan}

Berdasarkan hasil dan bahasan, maka dapat ditarik kesimpulan sesuai tujuan penelitian. Integrasi sistem minimum berbasis mikrokontroler Arduino sebagai CIA terkendali sinyal DTMF berupa dua buah modul gateway. Kedua modul tersebut, yaitu gateway A1 dan gateway A2 digabung menjadi satu kesatuan sistem yang di dalamnya terdiri atas beberapa rangkaian elektronika. Modul gateway A1 merupakan antarmuka yang terhubung dengan perangkat komunikasi berbasis sistem komunikasi radio, sedangkan modul gateway A2 merupakan antarmuka gateway yang terhubung dengan perangkat komunikasi berbasis teleponi.

Pemrograman terhadap sistem CIA berbasis Arduino $I D E$, meliputi penentuan algoritma dan penulisan sintaks. Pemrograman merupakan bentuk pengendalian terhadap sistem minimum pada perangkat komunikasi berbasis sistem komunikasi radio dan teleponi (PSTN atau GSM). Pengendalian berkait dengan penyambungan dan pemutusan koneksi perangkat komunikasi berbasis frekuensi radio dan teleponi.

Simulasi meliputi a) pemberian kondisi terhadap jalur masukan rangkaian detektor dering dan diamati kondisi keluaran dari rangkaian tersebut, b) pemberian kondisi terhadap rangkaian Voice Operated Transmit (VOX) dengan pemberian kondisi berupa audio pada jalur masukan dan jalur keluaran dihubungkan ke radio Motorola GM338, c) pemberian kondisi terhadap terhadap rangkaian off-hook terhadap perangkat telepon yang terhubung dengan saluran telepon, d) pemberian kondisi terhadap masukan pada jalur masukan modul busy tone dengan nada busy tone dengan frekuensi 425 hertz dalam periode 0,5 detik, e) pemberian kondisi terhadap dial-up nomor telepon melalui rangkaian switching untuk dial-up nomor telepon, dan f) perekaman dan pemutaran kembali suara dengan modul perekam dan penyimpan suara, berupa (i) perekaman suara dan (ii) pemutaran kembali suara. 


\section{Daftar Pustaka}

[1] J.T.J. Penttinen. "Introduction," in The Telecommunications Handbook: Engineering Guidelines for Fixed, Mobile and Satellite Systems. Chichester, WS: John Wiley \& Sons, Ltd., 2015, pp. 1-19.

[2] R. Horak, "Public Switched Telephone Network," in Telecommunications and Data Communications Handbook. Hoboken, NJ: John Wiley \& Sons, Inc., 2007, pp. 200-246.

[3] B. Kushnick. (2013, January, 7). What Are the Public Switched Telephone Networks, 'PSTN' and Why You Should Care?. [Online]. Available: http://www.huffingtonpost.com/brucekushnick/public-switched-telephonenetworks_b_2377773.html

[4] Direktorat Jenderal Pos dan Telekomunikasi, Departemen Perhubungan, (2005, Februari, 4). "Keputusan Direktur Jenderal Pos dan Telekomunikasi Nomor 13/Dirjen/2015, tentang Persyaratan Teknis Perangkat Videophone PSTN, Direktur Jenderal Pos dan Telekomunikasi". [Online]. Tersedia http://www.postel.go.id/downloads/41/20120120135504KEPUTUSAN_DIRJEN_POSTEL_NOMOR_13_2005.pdf

[5] ITU. "ITU History". [Online]. Available: http://www.itu.int/en/about/Pages/default.aspx.

[6] A.A. Huurdeman, "Cellular Radio," in The Worldwide History of Telecommunications, Hoboken, NJ: John Wiley \& Sons, Inc., 2003, p. 529.

[7] R. Sherman. (1999). Radio Communication System. [Online]. Available: 101/sys/ship/weaps/radio.htm.

[8] I. Setyawibawa dan A. Goeritno, "Rancang Bangun Sistem Komunikasi Radio Berbasis Digital Trunking Untuk Sarana Komunikasi pada Pengelolaan Jalan Tol Trans Sumatera," di Prosiding Seminar Nasional Teknologi dan Informatika (SNATIF ke-4 Tahun 2017), Fakultas Teknik, Universitas Muria Kudus, 2017, hlm. 181-193.

[9] Worldwide telecommunications system using satellites, by R.A. Wiedeman and P.A. Monte. (1999, June, 22). U.S. 5915217 A [Online].

Available:

http://patentimages.storage.googleapis.com/pdfs/US5915217. pdf

[10] W.S. Yoon and Y.D. Kim, "Satellite Communications Systems Applications," in Systems, Controls, Embedded Systems, Energy, and Machines, Richard C. Dorf, Editor, Boca Raton, FL: CRC Press, 2006, pp. 15.9.-15.28.

[11] L. Schenker. (1960, January). "Pushbutton Calling with a Two-Group Voice-Frequency Code," in The Bell System Technical Journal, (Version of Record Online: 29 Jul 2013). 39 (1), pp. 235-255. [Online]. Available: https://ia902707.us.archive.org/11/items/bstj39-1-235/bstj391-235.pdf

[12] F. Durda. (2006). Dual Tone Multi-Frequency (Touch-Tone®) Reference. [Online]. Available: http://nemesis.lonestar.org/reference/telecom/signaling/dtmf. html

[13] A.Z. Dodd, The Essential Guide to Telecommunications, $5^{\text {th }}$ Edition. Upper Saddle River, NJ: Prentice Hall, 2012, p. 183.

[14] Communications Interface Adapter, by S.F. Davidson, D.G Maglaya, D.A. Sofia, S.J. Collar, J.J. Stone. (1999, Nov., 25),
WO Patent 1999060723 A1, [Online]. Available: https://www.google.com/patents/WO1999060723A1?cl=en

[15] M.A. Seibert, A.J. Culotta, Jr. "Communications interface for wireless communications headset". U.S. Patent 6745014 B1, June 1, 2004

[16] M.A. Mazidi, S. Naimi, and S. Naimi, The AVR Microcontroller and Embedded Systems: Using Assembly and C. Upper Saddle River, NJ: Prentice Hall, 2011, pp. 40-43.

[17] S.F. Ginting, A. Goeritno, dan R. Yatim , "Kinerja Sistem Pengontrolan Berbantuan Sensor Voice Recognition dan Mikrokontroler ATmega16 untuk Pengoperasian Aktuator," di Prosiding SNTI V-2016 Universitas Trisakti, Jakarta, 18 Mei 2016, hlm. 359-365.

[18] A. Goeritno, dan S.F. Ginting, "Prototipe Sistem Pengontrolan Berbasis Voice Recognition Sensor dan Mikrokontroler untuk Pengoperasian Aktuator," pada JUTEKS Jurnal Teknik Elektro dan Sains, Program Studi Teknik Elektro Fakultas Teknik Universitas Ibn Khaldun Bogor, vol. 3, no. 2, Oktober 2016. [Online]. 3(2), hlm. 7-15. Tersedia di: http://ejournal.uika-

bogor.ac.id/index.php/JUTEKS/article/view/331/eng.

[19] B. Massimo and M. Shiloh. (2015, December). Getting Started with Arduino. (3rd Edition). [Online]. Available: http://www.esc19.net/cms/lib011/TX01933775/Centricity/Do main/110/make_gettingstartedwitharduino_3rdedition.pdf

[20] J. Purdum. (2012, September 10). Beginning C for Arduino: Learn C Programming for the Arduino and Compatible Microcontrollers. (1st ed.) [Online]. Available: http://www.lakos.fs.uni-

lj.si/images/Predmeti/MK/2014/Beginning\%20C\%20for\%20 Arduino.pdf.

[21] Motorola. (2010, Oct., 5). How to Build Voice Activated Switch. [Online]. Available:

http://www.circuit-finder.com/categories/sensor/soundsensor/443/voice-activated-switch

[22] Winbond. (2003, June). ISD2532/40/48/64: Single-Chip Multiple-Messages, Voice Record/Playback Device 32-, 40-, 48-, and 64-Second Duration. San Jose, CA: Winbond Electronics Corp. [Online]. Available: http://www.ozitronics.com/data/ISD2532.pdf.

[23] Busy tone detecting method and apparatus, by Z. Weining. (2011). CN Patent 101272420 B, [Online]. Available: https://encrypted.google.com/patents/CN101272420B?cl=en $\& \mathrm{hl}=$ en\&output=html_text.

[24] T.M. Cover and J.A. Thomas, Elements of Information Theory, Second Edition. Hoboken, NJ: John Wiley \& Sons, Inc., 2006, pp. 524-548.

[25] S.M. Redl, M.K. Weber, and M.W. Oliphant, GSM and Personal Communication Handbook, Norwood, MA: Artech House, Inc., 1998, pp. 172-173.

[26] CadSoft. EAGLE Easily Applicable Graphical Layout Editor Manual Version 5. Palm Beach, FL: CadSoft Computer Inc., pp. 37-80, 2010. 